\title{
Preparation and Aggregate Formation of O-Hydroxypropyl-N-Laurel Acyl Chitosan Ramification
}

\author{
Funeng Tan ${ }^{1,}{ }^{*}$, Zhixin Zhang $^{1}$, Yunbo Zhou ${ }^{1}$, Weiping Sui ${ }^{2}$ \\ ${ }^{1}$ Chemical and engineering institute, Wenshan University, Wenshan, 663000, Yunnan, China \\ ${ }^{2}$ College of Chemistry and Chemical Engineering, University of Jinan, Jinan, 250022, China \\ *Corresponding author
}

\begin{abstract}
A new kind of amphiphilic derivatives of chitosan, O-hydroxypropyl-N-laurel acyl chitosan(O-HP-N-LACHS) ramification were synthesized. The chemical structures of the chitosan derivatives were characterized by FTIR, ${ }^{1}$ HNMR. The surface and aggregate properties were studied by means of surface tension and fluorescence measurements. Results showed that O-hydroxypropyl-N-laurel acyl chitosan can concentrate on the surface to decrease the surface tension and can associate with hydrophobic chains to form aggregates in the solution. The abilities to decrease the surface tension and to form aggregates were promoted by increasing the DS of hydrophobic group.
\end{abstract}

Keywords-amphiphilic; O-hydroxypropyl-N-laurel acyl chitosan ramification; surface activity; aggregate .

\section{INTRODUCTION}

Aggregation of amphiphilic polymers is of growing interest with respect to biological importance and pharmaceutical or biotechnological applications ${ }^{[1]}$. Recently, solution properties of block copolymer or self-aggregates or hydrophobized water-soluble polymers have been extensively studied ${ }^{[2,3]}$. Biopolymers and various synthetic charged or nonionic polymers have been used as hydrophilic backbone to prepare amphiphilic polymers by hydrophobic substitution ${ }^{[4,5]}$. Among these water-soluble polymers, naturally occurring polysaccharides which are biodegradable polyhydroxyl compounds show unique properties such as the formation of a hydrogel or liquid crystal $^{[6,7]}$.

Chitosan(CHS), next to cellulose, is the second most plentiful biomass and has a repeated structure of $(1,4)$ linked-2-amino-2-deoxy-b-D-glucan. Since chitosan is already known as a biocompatible, biodegradable and almost nontoxic material ${ }^{[8]}$. Chitosan is soluble in aqueous solutions of various acids, but chitosan molecules have no amphiphilic property and cannot form micelles in water. Apart from its biodegradable character in physiological conditions, chitosan has reactive amine and hydroxyl groups ${ }^{[9]}$, which offer possibilities of modifications, graft reactions and ionic interactions. For the past two decades, significant efforts have been devoted to develop novel polymeric carriers that form compact micellar structure in an aqueous milieu, including amphiphilic block copolymers $^{[10]}$ and hydrophobically modified water- soluble polymers. These micellar or nanoparticles can be used as peptide delivery system, gene delivery system.

In this study, we aimed to prepare a new group of amphiphilic ramification of O-hydroxypropyl-N-laurel acyl chitosan (O-HP-N-LACHS). The surface and aggregate properties of O-HP-N-LACHS were studied by surface tension and fluorescence measurement.

\section{EXPERIMENTAL}

\section{A. Materials}

Chitosan was provided by the Shanghai Biochemical Co. Ltd., China. Sodium hydroxide, acetone, isopropyl alcohol was purchased from Jinan chemical Co. Ltd China. lauroyl chloride was purchased from Yantai Luyang chemical Co. Ltd, China..

\section{B. Synthesis}

$1 \mathrm{~g}$ of chitosan was added in the mixture of $40 \mathrm{ml} 11 \%$ $\mathrm{HAc}$ and $100 \mathrm{ml} \mathrm{CH}_{3} \mathrm{OH}$ solution while stirring. After a period of time, $6.7 \mathrm{~g}$ of benzaldehyde was added in the mixture at $60^{\circ} \mathrm{C}$ and the mixture was kept for $24 \mathrm{~h}$ while stirring. Then added in the mixture of $40 \mathrm{ml}$ isopropyl alcohol and $2 \mathrm{ml} 20 \% \mathrm{NaOH}$ solution was kept for $2 \mathrm{~h}$ while stirring. $3.4 \mathrm{~g}$ propylene oxide were added to the mixture at $45^{\circ} \mathrm{C}$ and kept for $24 \mathrm{~h}$ while stirring. Added the product in the mixture of $40 \mathrm{ml}$ ethanol and $10 \mathrm{ml} 10 \%$ hydrochloric acid was kept for $15 \mathrm{~h}$ while stirring at $30^{\circ} \mathrm{C}$, The product was filtered with acetone and washed with ethanol. Then vacuum drying at $50^{\circ} \mathrm{C}$. Added in the mixture of $30 \mathrm{ml}$ isopropyl alcohol and $4 \mathrm{ml} 20 \%$ Sodium hydroxide solution was kept for $10 \mathrm{~min}$ while stirring at $70^{\circ} \mathrm{C}$. Then added lauroyl chloride in the mixture and kept for $5 \mathrm{~h}$. got O-hydroxypropyl-N-decanealkyl chitosan. The degree of the substitution (DS) is $9.9 \%, 17.8 \%, 24.1 \%$. DS defined as the number of bromododecane groups per 100 anhydroglucose units of chitosan, was determined by elemental analysis.

\section{Characterization}

IR spectra were recorded on Fourier-transform infrared spectrometer in $\mathrm{KBr}$ discs. ${ }^{1} \mathrm{H}-\mathrm{NMR}$ spectra were performed on a Bruker Avance 400 spectrometer by using $\mathrm{D}_{2} \mathrm{O}$ as solvent. 


\section{Measurement of surface tension}

The surface tension measurements of O-HP-N-LACHS solutions at various concentration were carried out on a DCA300 Tensionmeter with plate method of Wilbelmy at $25 \pm 0.1{ }^{\circ} \mathrm{C}$. All the solution were kept at roomtemperature for 2 day before surface tension measurement.

\section{E. Fluorescence measurements}

Steady-state fluorescence measurements were carried out on a RF-540 Spectrofluorimeter (Japan). The excitation wavelength of pyrene was $335 \mathrm{~nm}$. A known volume of pyrene in $\mathrm{MeOH}$ was put into a test tube and evaporated under a nitrogen purge to remove the solvent. Then, an aqueous solution of O-hydroxypropyl-N-laurel acyl chitosan was added into the test tube. The final concentration of pyrene was $1 \times 10^{-6} \mathrm{~mol} / \mathrm{dm}^{-3}$. The solutions were sonicated for $15 \mathrm{~min}$ in an ultrasonic bath and then kept at room temperature for $2 \mathrm{~h}$ before spectroscopic analysis. The hydrophobic index, $I_{1} / I_{3}$, was calculated as the ratio of the intensities at the first $(374 \mathrm{~nm})$ and the third $(385 \mathrm{~nm})$ vibrational peaks of monomeric pyrene in the pyrene emission spectra.

\section{RESULTS AND DISCUSSION}

\section{A. Characterization}

In the IR spectra of O-hydroxypropyl chitosan ( OHPCHS ) $b$ showed disappearance of aromatic peaks at $1500 \mathrm{~cm}^{-1}, 1580 \mathrm{~cm}^{-1}, 1600 \mathrm{~cm}^{-1}$ and $\mathrm{C}=\mathrm{N}$ characteristic absorption peak at $1634.5 \mathrm{~cm}^{-1}$, which showed Schiff base had disappeared. The peaks at $3432.8 \mathrm{~cm}^{-1}$ attributed to association reaction of hydroxy group and $1058.7 \mathrm{~cm}^{-1}$ attributed to stretching vibration absorption of C-O. Asymmetric stretching vibration absorption of $\mathrm{C}-\mathrm{O}-\mathrm{C}$ at $1060-1150 \mathrm{~cm}^{-1}$ had enhanced largely. These indicated that hydroxypropyl group had introduced to $-\mathrm{OH}$. In the IR spectra of O-HP-N-LACHS (c). The praks at $2968 \mathrm{~cm}^{-1}$, $1465 \mathrm{~cm}^{-1}$ attributed to stretching vibration absorption of $\mathrm{CH}_{3}, \quad 1375 \mathrm{~cm}^{-1}$ attributed to umbrella vibration absorption of $-\mathrm{CH}_{3}$ and $2922 \mathrm{~cm}^{-1}$ attributed to asymmetric stretching vibration of $-\mathrm{CH}_{2-}$. At the same time, the weaken of peak of amino indicated that alky group has introduced to amino.

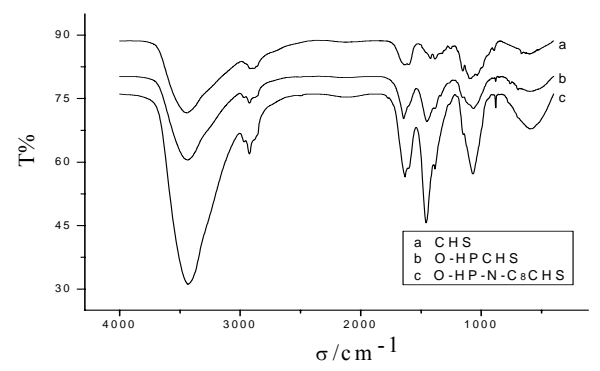

Figure 1. IR spectra of (a) CHS , (b) O-HPCHS, (c) O-HP-N-LACHS

Figure.2 showed the disappearance peaks of $\mathrm{C}_{2}$ at 2.192ppm, the peaks at 3.3-3.8 ppm showed overlapping absorption peak of $\mathrm{C}_{3}, \mathrm{C}_{4}$ and $\mathrm{C}_{5}$ beloned to protons of chitosan. The peak at $4.482 \mathrm{ppm}$ attributed to protons of $\mathrm{CH}_{2}-\mathrm{O}-\mathrm{CH}_{2-}\left(\mathrm{C}_{6} 、 \mathrm{C}_{7}\right)$, the peaks at $1.801 \mathrm{ppm}$, attributed to protons of -NH-. These indicated that the existence of hydrophobic group. The peak at $0.793 \mathrm{ppm}$ associated with overlapping absorption peak of $-\mathrm{CH}_{2^{-}}\left(\mathrm{C}_{10}\right)$. The peak at 1.253 ppm attributed to $-\mathrm{CH}_{2}\left(\mathrm{C}_{11} \sim \mathrm{C}_{20}\right)$ 。.

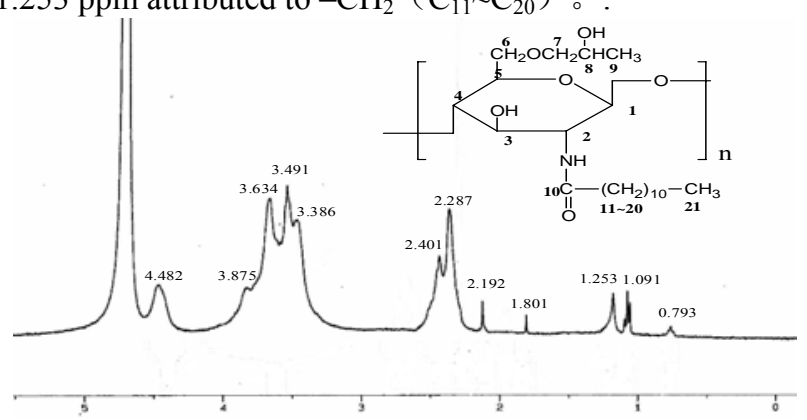

Figure 2. ${ }^{1} \mathrm{H}-\mathrm{NMR}$ spectrum of O-HP-N-LACHS

\section{B. Surface activity properties}

Figure 3 showed the surface tension concentration plots of O-HPCHS, O-HP-N-LACHS. O-HPCHS is a watersoluble polymeric compound, which has little surface activity property for there is no long chain hydrophobic group in the polymer. After hydrophobic group were introduced, the resulting derivatives, O-HP-N-LACHS are converted to amphiphilic polymers with these hydrophilic backbones substituted by hydrophobic groups. They adsorb on the surface with the hydrophilic backbone in the solution, while the hydrophobic groups point up towards the air to reduce the surface tension of water. When the concentration is big enough, the surface adsorption is complete and the surface tension no longer decreases.

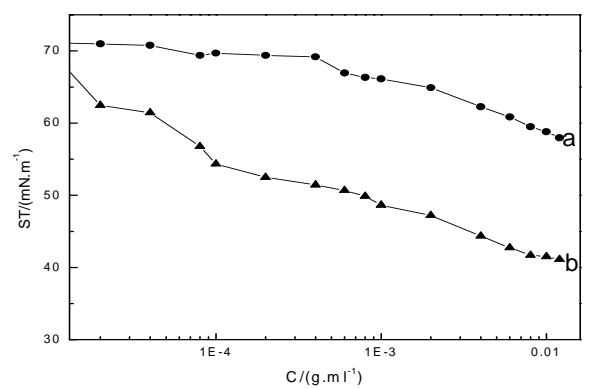

Figure 3. Surface tension concentration plots of (a) O-HPCHS and (b) OHP-N-LACHS

Figure. 4 showed the surface tension concentration plots of O-HP-N-LACHS with different degrees of substitution (DS). We could see that with the increase of degree of substitution (DS) of the hydrophobic group, the surface tension decreases at the same concentration of the derivatives, for there are more hydrophobic groups on the surface. The concentration of adsorption decreases for the same reason. 


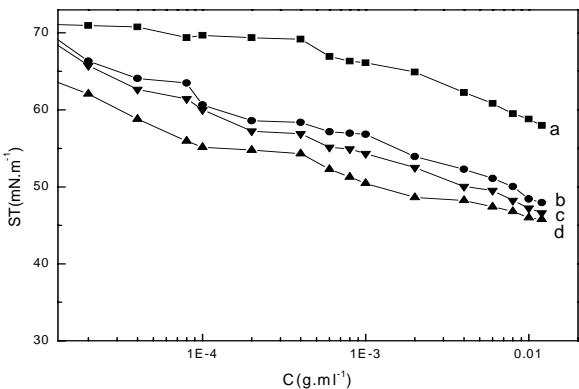

Figure 4. Surface tension concentration plots of (a) O-HPCHS and O-HPN-LACHS with different degrees of substitution (DS). (b) DS is $9.9 \%$, (c) DS is $17.8 \%$, (c) DS is $24.1 \%$.

\section{Aggregate formation}

In order to study the formation of aggregates in a solution of O-hydroxypropyl-N-laurel acylchitosan, fluorescence measurements were used to detect the emission spectra of pyrene in the solution. There are five peaks in the emission spectra of pyrene, and the emission intensity of the first peak $(374 \mathrm{~nm})$ and of the third peak $(385 \mathrm{~nm})$ is sensitive to the microenvironment. So the intensity ratio of the emission at 374 and $385 \mathrm{~nm}\left(\mathrm{I}_{1} / \mathrm{I}_{3}\right)$ has been used to monitor the solution behavior of surfactants and/or polymers. A bigger $\mathrm{I}_{1}=\mathrm{I}_{3}$ value means a greater polarit of the solution around pyrene. Therefore, the formation of the aggregates with a hydrophobic inner core can be detected by means of plotting $\mathrm{I}_{1}=\mathrm{I}_{3}$ versus polymer concentration.

Figure. 5 showed the $I_{1} / I_{3}$ value of pyrene in solution as a function of O-HPCHS, O-HP-N-LACHS concentration. When the concentration of O-HP-N-LACHS is above $10^{-3}$ $\mathrm{gmL}^{-1}$, the $\mathrm{I}_{\mathrm{l}} / \mathrm{I}_{3}$ value gradually decreases, indicating that the microenvironment around pyrene is getting more hydrophobic. It can be interpreted as the formation of aggregates with the hydrophobic core getting more compact. But the $\mathrm{I}_{1} / \mathrm{I}_{3}$ value of $\mathrm{O}$-HPCHS changed a little with the concentration increased. It showed that O-HPCHS is hardly to form aggregates for there is no hydrophobic group. After modified O-HP-N-LACHS is easy to formed aggregates by their hydrophobic chains in solution.

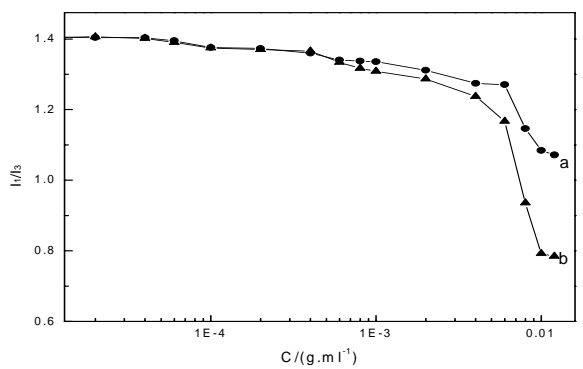

Figure $5 . \mathrm{I}_{1} / \mathrm{I}_{3}$ value of O-HPCHS and O-HP-N-LACHS as a function of polymer concentration

The plots of $I_{1} / I_{3}$ values versus polymer concentrations for O-HP-N-LACHS chitosan composed of different degrees of DS are shown in Figure 8. With the increase of concentration, the $\mathrm{I}_{1} / \mathrm{I}_{3}$ value decreases, and the O-HP-NLACHS of the higher DS decreases first, which indicates that increasing of DS could make it easy for aggregates to form for there are more hydrophobic chains to associate. At the same concentration, the higher the DS, the lower the $\mathrm{I}_{1} / \mathrm{I}_{3}$ value. This means that the hydrophobicity increases with increases in the DS. This is consistent with the results of the surface tension studies.

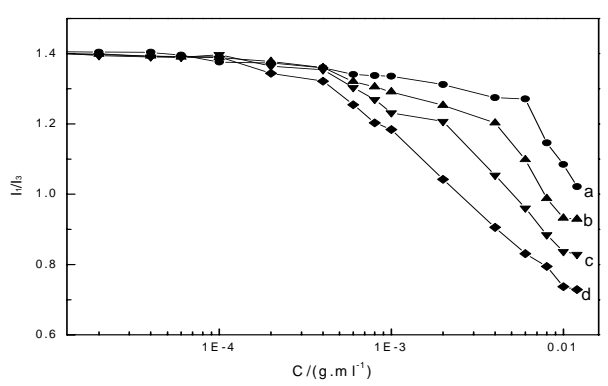

Figure 6. $\mathrm{I}_{1} / \mathrm{I}_{3}$ value of of (a) O-HPCHS and O-HP-N-LACHS with different degrees of substitution (DS). (b) DS is $9.9 \%$, (c) DS is $17.8 \%$, (c) DS is $24.1 \%$.

\section{CONCLUSIONS}

A new group of amphiphilic ramification of O-HP-NLACHS ramification were characterized by elemental analysis, FTIR and ${ }^{1} \mathrm{H}$ NMR. It can decrease surface tension and formed aggregates in the solution. With the concentration increased, the surface tension decreased and the aggregates formed in solution. With the concentration increased, the surface tension decreased and the aggregates formed in solution. The ability to decrease the surface tension and form aggregates was promoted by increasing the DS of hydrophobic group. O-HP-N-LACHS ramification has the character of polymer surfactant. In a word, the new type of amphiphilic ramification of chitosan could be widely used in many fields in future.

\section{ACKNOWLEDGEMENTS}

The research work was supported by Department of Applied Basic Research for Youth of Yunnan (No 2012FD058)

\section{REFERENCES}

[1] Jones M., Leroux J., Polymeric micelles-a new generation of colloidal drug carriers. Euro. J. Pharm. Biopharm, 48, pp. 101-111, 1999.

[2] Buhler E., Rinaudo M., Structural and dynamical properties of semirigid polyelectrolyte solutions: A light-scattering study, Macromolecules, 33, pp. 2098-2031, 2000.

[3] Lopes J.R., Watson L., Investigation of self-assembly and micelle polarity for a wide range of ethylene oxide-propylene oxide-ethylene oxide block copolymers in water, Langmuir, 14, pp. 750-756, 1998

[4] Ogino K., Onoe Y., Abe M., Reduction of surface tension by novel polymer surfactants, Langmuir, 6 pp. (1990) 1330-1338.

[5] Majeti N. V., Ravi K, A review of chitin and chitosan applications, Reactive \& Functional Polymers, 46(1), pp. 1-27, 2000. 
[6] Campos J. B., Lourencao B. C., Omuro Lupetti K., Development of a method employing chitosan to remove metallic ions from wastewater, Quimica Nova, 30(4), pp. 879-884, 2007.

[7] Montembault A., Viton C., Domard A., Rheometric study of the gelation of chitosan in a hydroalcoholic medium, Biomaterials, 26, pp 1633-1643.

[8] Skorik Y. A., Gomes C. A. R., N-(2-Carboxyethyl) chitosans: regioselective synthesis, characterisation and protolytic equilibria, Carbohydr. Res., 338, pp. 271-276, (2003).
[9] Kogan G., Skorik A., Antioxidant and antimutagenic activity of N-(2carboxyethyl) chitosan, Toxicology and Applied Pharmacology, 201, pp. 303-310, 2004

[10] Nakanishi, T., Fukushima, S., Okamoto, K., Suzuki, M., Preparation and biological characterization of polymeric micelle drug carriers with intracellular $\mathrm{pH}$-triggered drug release property: tumor permeability,J. Control.Release, 74, pp. 295-302, 2001. 